\title{
OC08 - Care for the children with severe forms of atopic dermatitis
}

Ivona Mikulenková (Czech Republic)'; Miroslav Kobsa (Czech

Republic) ${ }^{1}$; Jana Mičková-Domitrová (Czech Republic) ${ }^{1}$

${ }^{1}$ Hospital Nový Jičín

Theme: Complex health care and chronic disease management.

Keywords: Apheresis, atopic dermatitis, immunoglobulins, immunoadsorption

Fast progress in medicine brings new development and new methods in treatment for children and youth with atopic dermatitis.

There is an increasing number of children with this disease and in some cases the available treatment is failing. In our hospital we offer new methods of treatment for this group of patients.

Objectives:

- describe the whole process of selecting patients for particular treatment

- analyse our unit experience and identify advantages and barriers in the process

- evaluate the results of specific treatments

- gain insight of family experience

- European statistics of the patients receiving treatment of immunoadsorption.

Methods:

- standard questionnaire given to the families

- research and co-operation with the European centres.

Results and conclusion

- European statistical results are still in process of evaluation

- further development of our services

- there are clear benefits to the children

- development of system to make particular treatment more accessible.

\section{OC09 - Early maternal contact has an impact on preterm infants' brain systems that manage stress}

Evalotte Mörelius (Sweden)ㄹ; Annika Örtenstrand (Sweden)²; Elvar Theodorsson (Sweden) ${ }^{3}$; Anneli Frostell (Sweden) ${ }^{3}$

${ }^{1}$ Linköping University Department of social and welfare studies; ${ }^{2}$ Karolinska Institutet; ${ }^{3}$ Linköping University 